\title{
Publisher Correction: Common brain disorders are associated with heritable patterns of apparent aging of the brain
}

Tobias Kaufmann (1), Dennis van der Meer ®D, Nhat Trung Doan, Emanuel Schwarz, Martina J. Lund, Ingrid Agartz, Dag Alnæs (D), Deanna M. Barch, Ramona Baur-Streubel, Alessandro Bertolino, Francesco Bettella, Mona K. Beyer, Erlend Bøen, Stefan Borgwardt (D), Christine L. Brandt, Jan Buitelaar (D), Elisabeth G. Celius (D), Simon Cervenka, Annette Conzelmann, Aldo Córdova-Palomera, Anders M. Dale, Dominique J. F. de Quervain, Pasquale Di Carlo (D), Srdjan Djurovic (D), Erlend S. Dørum, Sarah Eisenacher, Torbjørn Elvsåshagen, Thomas Espeseth (1), Helena Fatouros-Bergman, Lena Flyckt, Barbara Franke (D), Oleksandr Frei, Beathe Haatveit, Asta K. Håberg, Hanne F. Harbo, Catharina A. Hartman, Dirk Heslenfeld, Pieter J. Hoekstra, Einar A. Høgestøl, Terry L. Jernigan, Rune Jonassen, Erik G. Jönsson, Karolinska Schizophrenia Project (KaSP), Peter Kirsch (1), Iwona Kłoszewska, Knut K. Kolskår, Nils Inge Landrø, Stephanie Le Hellard, Klaus-Peter Lesch (D), Simon Lovestone, Arvid Lundervold (1), Astri J. Lundervold (D), Luigi A. Maglanoc, Ulrik F. Malt (1D, Patrizia Mecocci, Ingrid Melle, Andreas Meyer-Lindenberg (1), Torgeir Moberget, Linn B. Norbom, Jan Egil Nordvik, Lars Nyberg, Jaap Oosterlaan, Marco Papalino,

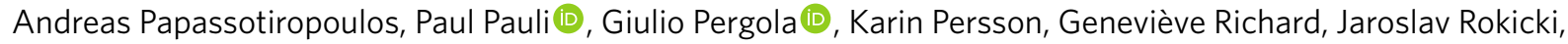
Anne-Marthe Sanders, Geir Selbæk, Alexey A. Shadrin, Olav B. Smeland (D, Hilkka Soininen, Piotr Sowa, Vidar M. Steen, Magda Tsolaki, Kristine M. Ulrichsen, Bruno Vellas, Lei Wang (D), Eric Westman (D), Georg C. Ziegler (1), Mathias Zink, Ole A. Andreassen (i) and Lars T. Westlye (i)

Correction to: Nature Neuroscience https://doi.org/10.1038/s41593-019-0471-7, published online 24 September 2019.

In the version of this article initially published, spaces were missing in the names of Stephanie Le Hellard and Pasquale Di Carlo. The errors have been corrected in the HTML and PDF versions of the article.

Published online: 17 December 2019

https://doi.org/10.1038/s41593-019-0553-6

(c) The Author(s), under exclusive licence to Springer Nature America, Inc. 2019

\section{Publisher Correction: Exome sequencing in amyotrophic lateral sclerosis implicates a novel gene, DNAJC7, encoding a heat-shock protein}

Sali M. K. Farhan (1), Daniel P. Howrigan (D), Liam E. Abbott, Joseph R. Klim (1D, Simon D. Topp (1), Andrea E. Byrnes, Claire Churchhouse, Hemali Phatnani, Bradley N. Smith, Evadnie Rampersaud, Gang Wu(D, Joanne Wuu, Aleksey Shatunov, Alfredo lacoangeli, Ahmad Al Khleifat, Daniel A. Mordes, Sulagna Ghosh, ALSGENS Consortium, FALS Consortium, Project MinE Consortium, CReATe Consortium, Kevin Eggan (D), Rosa Rademakers, Jacob L. McCauley Di Rebecca Schüle, Stephan Züchner, Michael Benatar, J. Paul Taylor, Michael Nalls, Marc Gotkine, Pamela J. Shaw, Karen E. Morrison, Ammar Al-Chalabi (B), Bryan Traynor, Christopher E. Shaw, David B. Goldstein (1D, Matthew B. Harms, Mark J. Daly 10 and Benjamin M. Neale $\mathbb{D}$

Correction to: Nature Neuroscience https://doi.org/10.1038/s41593-019-0530-0, published online 25 November 2019.

In the version of this article initially published, the affiliations of three authors were incorrect.

Liam E. Abbott should have been associated with Analytic and Translational Genetics Unit, Department of Medicine, Massachusetts General Hospital and Harvard Medical School, Boston, MA, USA; Program in Medical and Population Genetics, Broad Institute of Harvard and MIT, Cambridge, MA, USA; and Stanley Center for Psychiatric Research, Broad Institute of Harvard and MIT, Cambridge, MA, USA.

Ammar Al-Chalabi should have been associated with Department of Basic and Clinical Neuroscience, Maurice Wohl Clinical Neuroscience Institute, King's College London, London, UK; and Department of Neurology, King's College Hospital, London, UK.

Bryan Traynor should have been associated with Molecular Genetics Section, Laboratory of Neurogenetics, National Institute on Aging, Bethesda, MD, USA; and Department of Neurology, Johns Hopkins University, Baltimore, MD, USA.

The error has been corrected in the PDF and HTML versions of this article.

Published online: 19 December 2019

https://doi.org/10.1038/s41593-019-0570-5

(C) The Author(s), under exclusive licence to Springer Nature America, Inc. 2019 